\title{
Carlo Aymonino: The Critical Curiosity of a Visionary Architect
}

\author{
Maurizio Sabini
}

Exhibition Review / CRITICISM

\begin{abstract}
Exhibition
"Carlo Aymonino. Fedelta' al tradimento / Loyalty to Betrayal"

Triennale, Milan, May 14 - August 22, 2021

From an idea by Livia and Silvia Aymonino

Curated by Manuel Orazi

Exhibition Design by Federica Parolini

Catalog edited by Manuel Orazi (Milan: Electa, 2021)
\end{abstract}

A major retrospective on Carlo Aymonino, upon the tenth anniversary of his passing (falling last year in 2020), has been recently inaugurated at the Milan Triennale and will run until August 22, 2021. The show tries to address an important gap in our contemporary architectural culture, as rightly noted by Triennale's President Stefano Boeri: "[with this exhibition] the Triennale is filling the large and inexplicable void that has been created around the figure of one of the most talented and influential architects of our twentieth century." 1

Born out of an idea by Livia and Silvia Aymonino (Carlo's daughters) and curated by Manuel Orazi, the exhibition offers, through a theatrically unfolded narration, aptly assigned to the expertise of scenographer Federica Parolini, an articulated, multi-layered and rich overview of Aymonino's works and life (1926-2010). And, especially, drawings.

Artistically born as a painter, to move later into architecture under the pragmatic pressure of his father Aldo (a military officer from Piedmont) who encouraged the young Carlo to intern in 1944 in the office of his own cousin, influential and well connected Roman architect Marcello Piacentini, Aymonino never renounced to nurture his natural passion for 
drawing. Thus, the visitors of the exhibition are really hit by a figurative maelstrom of images, that attest to Aymonino's incessant drive to explore, and reflect upon, architecture, art and life in their varied complexities. Different techniques, from simple ink pen on paper, to marker, pastel, lithography, and mixed technique (his favorite), as well as a wide range of formats (from napkin sketches to large axononometric studies), show an unsatiable search for form, spatial relationships, and the complex beauty of humanity. (Figs. 1, 2.) All framed within a variety of contexts: from professional studies to vacation trips, nude studies and humorous journals created for his children. Drawing was for Aymonino a way to explore, understand and imagine reality, present and future. As a true, visionary architect is supposed to do. "Drawing is theory" I once posited, ${ }^{2}$ and Aymonino's works clearly show drawing as a search for knowledge, even though he was always very wary to establish direct ties between drawing and design, theory and practice. He never missed the chance to note his "rejection of [any] compact and programmatic coherence: it is not necessary for theory and practice to coincide, for the personality to be homogeneous and unitary; the more one seeks and experiments, the more diversity, contradictions, negations, and obstacles arise." ${ }^{3}$ Yet, for example, the tension between architectural figuration and urban studies remained a constant in Aymonino's professional and scholarly career, coming to a moment of high synthesis perhaps only in the case of the school campus in Pesaro, as Aymonino himself has admitted:

The Pesaro Campus seems to me the only successful case, in my experience, in which urban analysis, albeit in a mediated form, joins the various design components and contributes to the architectural solution. The anonymity of the southern suburbs of Pesaro suggests the desire for something representative, something that constitutes image and memory, the absent baggage of collective identity. ${ }^{4}$

The Pesaro Campus occupies, rightly so, a central role in the exhibition, especially with Aymonino's celebrated drawing (aptly blown up to frame and illustrate a landmark partition within the exhibition space), II liceo nella tempesta di Giorgione (The High-School in Giorgione's Storm) - a witty title given to one of his studies for the volumetric articulation of the school (through one of his signature, and most beautiful, perspective views), imagined against a backdrop evoking the famous painting of the Venetian Renaissance master. (Figs. 3, 4.)

As a gifted artist, Aymonino particularly enjoyed the figurative power of the perspective view (or the sectional perspective for that matter - famous are the ones for the Gallaratese complex in Milan). As a skillful architect, he also clearly understood and appreciated, as did some masters of early Modernism, such as Otto Wagner, Corbu and Mies (all of whom extensively employed the perspective view as a preferred mode of study and representation), that the perspective view is the ultimate validation of 


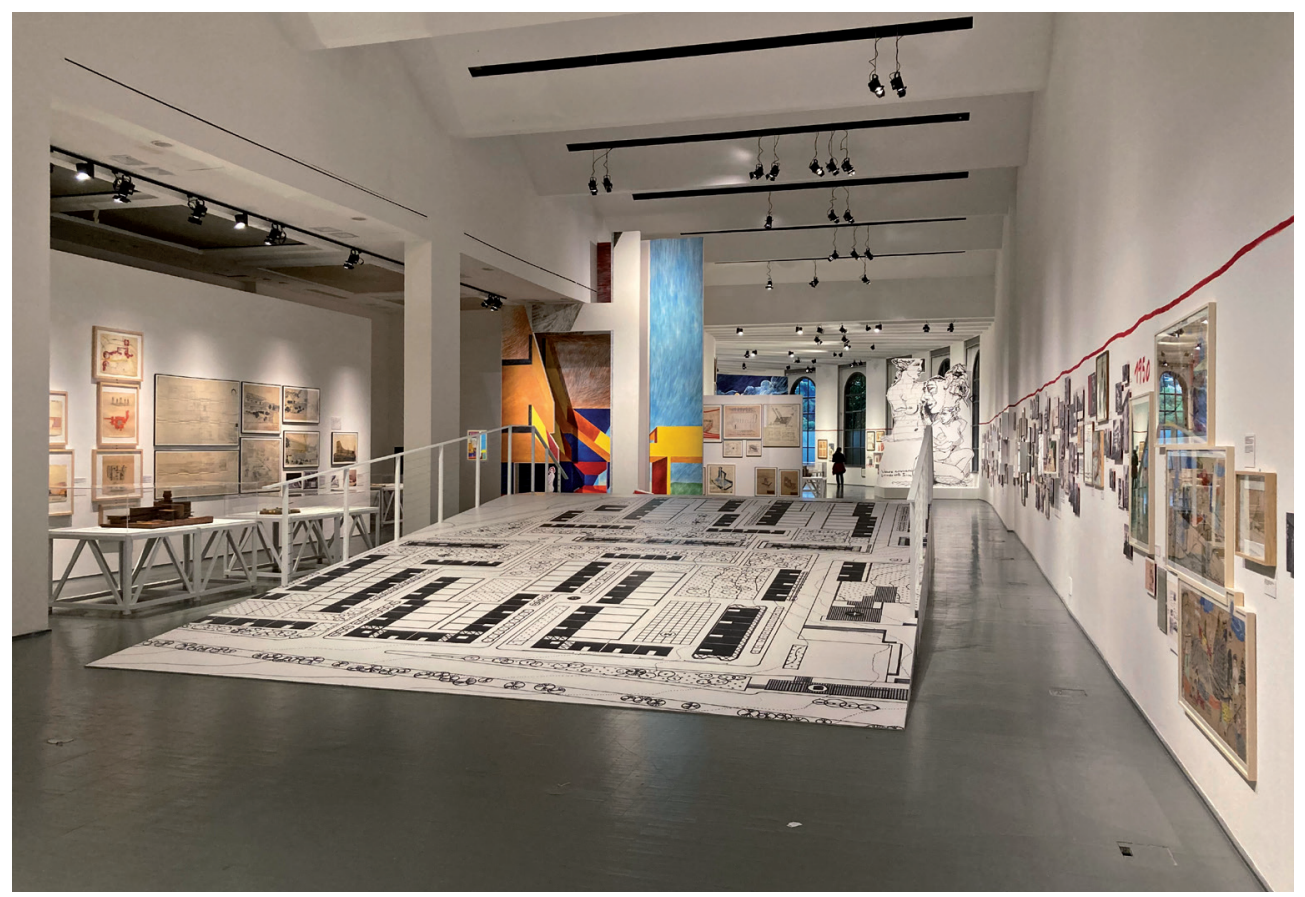

Figure 1. Entryway to the exhibition (on the ramp floor, a reproduction of the social housing neighborhood plan for the Spine Bianche in Matera, 1954-59).

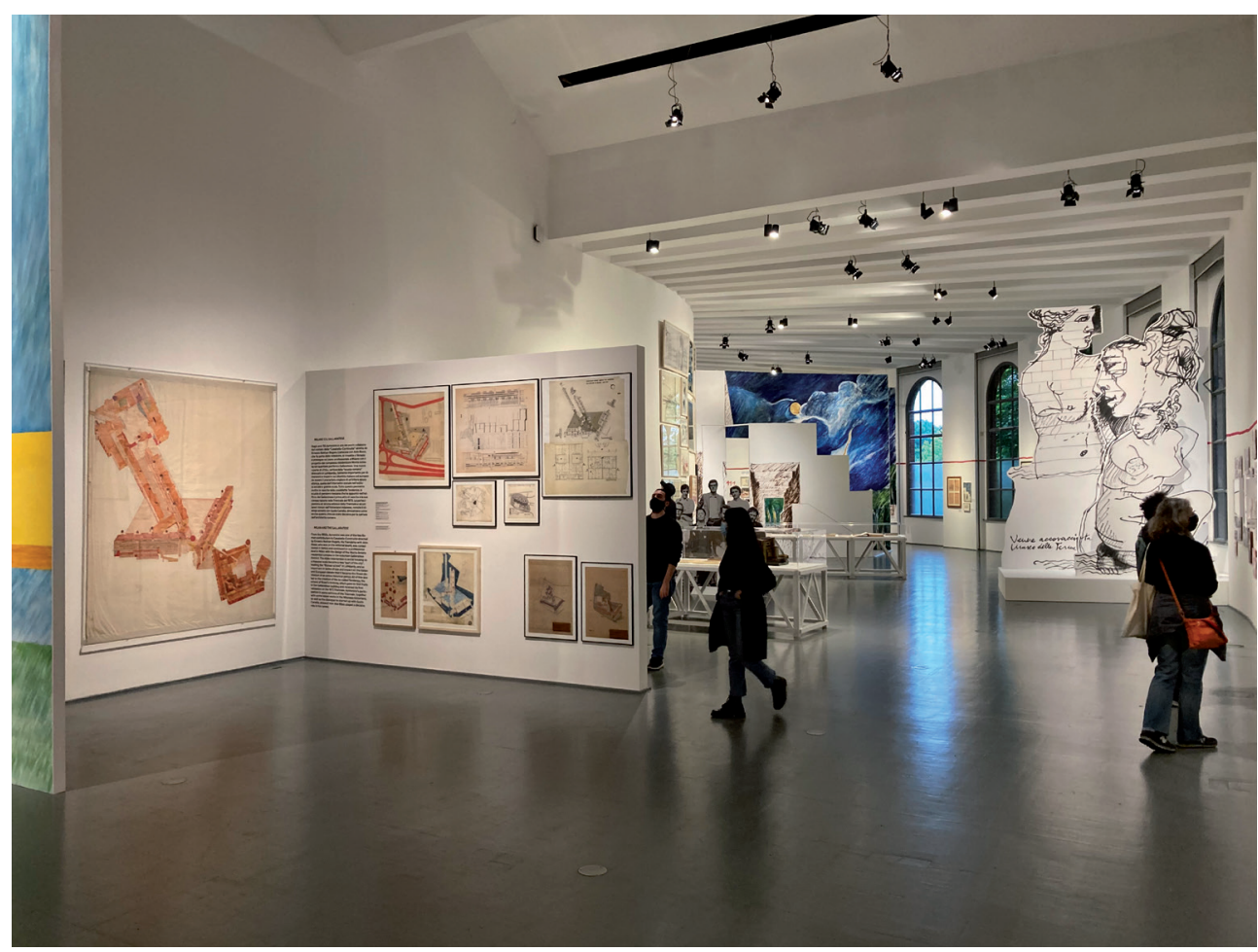

Figure 2. View of the area dedicated to the Gallaratese housing complex in Milan (1967-72). On the left: axononometric study Gallaratese, a Part of the City (1976), ink and pencils on prints, mounted on canvas, $233.5 \times 197.4 \mathrm{~cm}\left[7 \frac{1}{2} \times 6 \frac{1}{2} \mathrm{ft}\right.$.], collection Centre Pompidou, Paris. The study (done after the completion of the Gallaratese project) shows a vision of an imaginary "urban part," composed with the built housing complex in Milan (middle), and the yet to be built high-school (lower right) and an initial version of the never built civic center (upper left), both in Pesaro. 


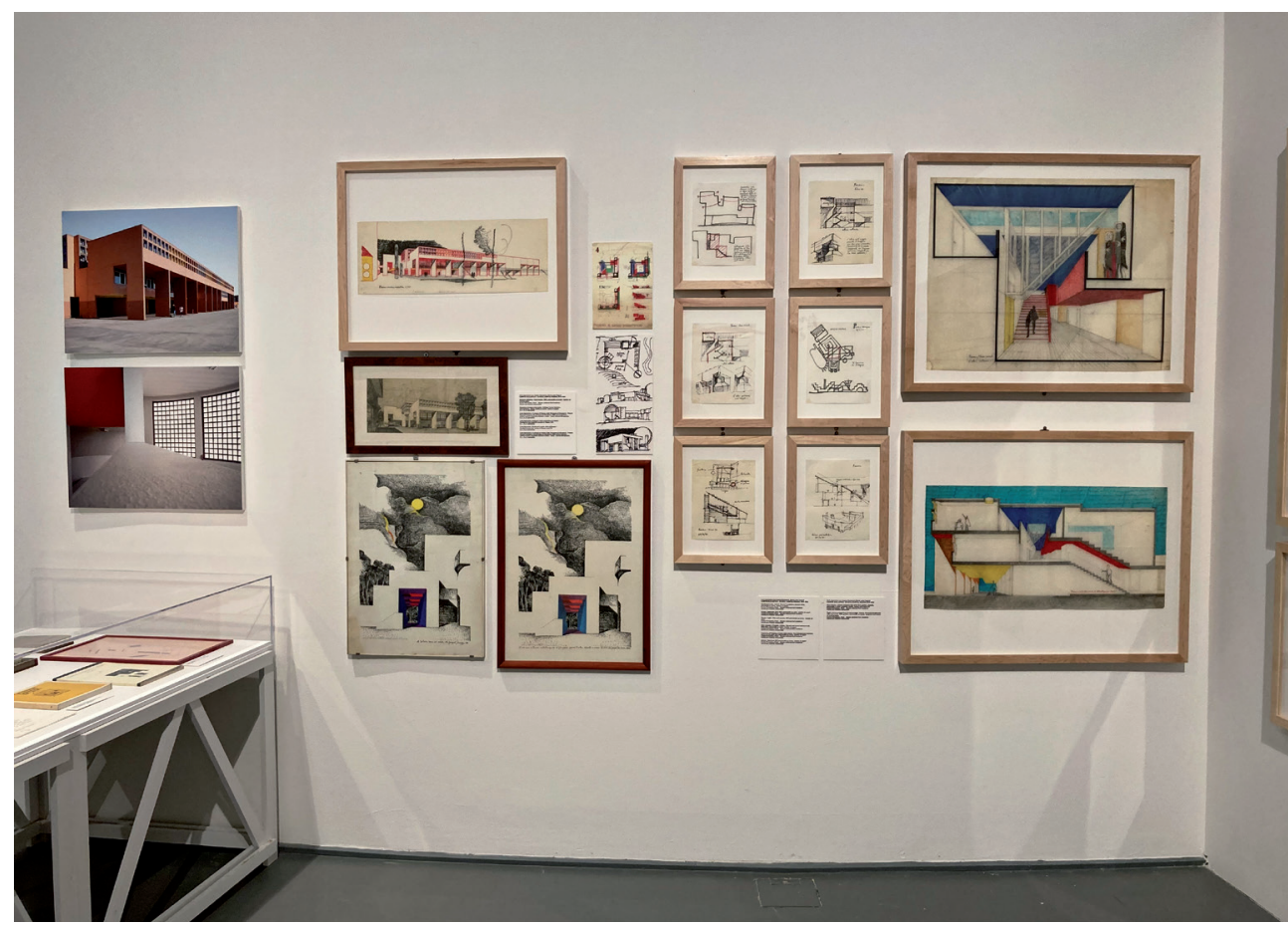

Figure 3. Design studies (mostly sectional perspectives and perspective views) and photographs of the high-school in Pesaro (1970-84).

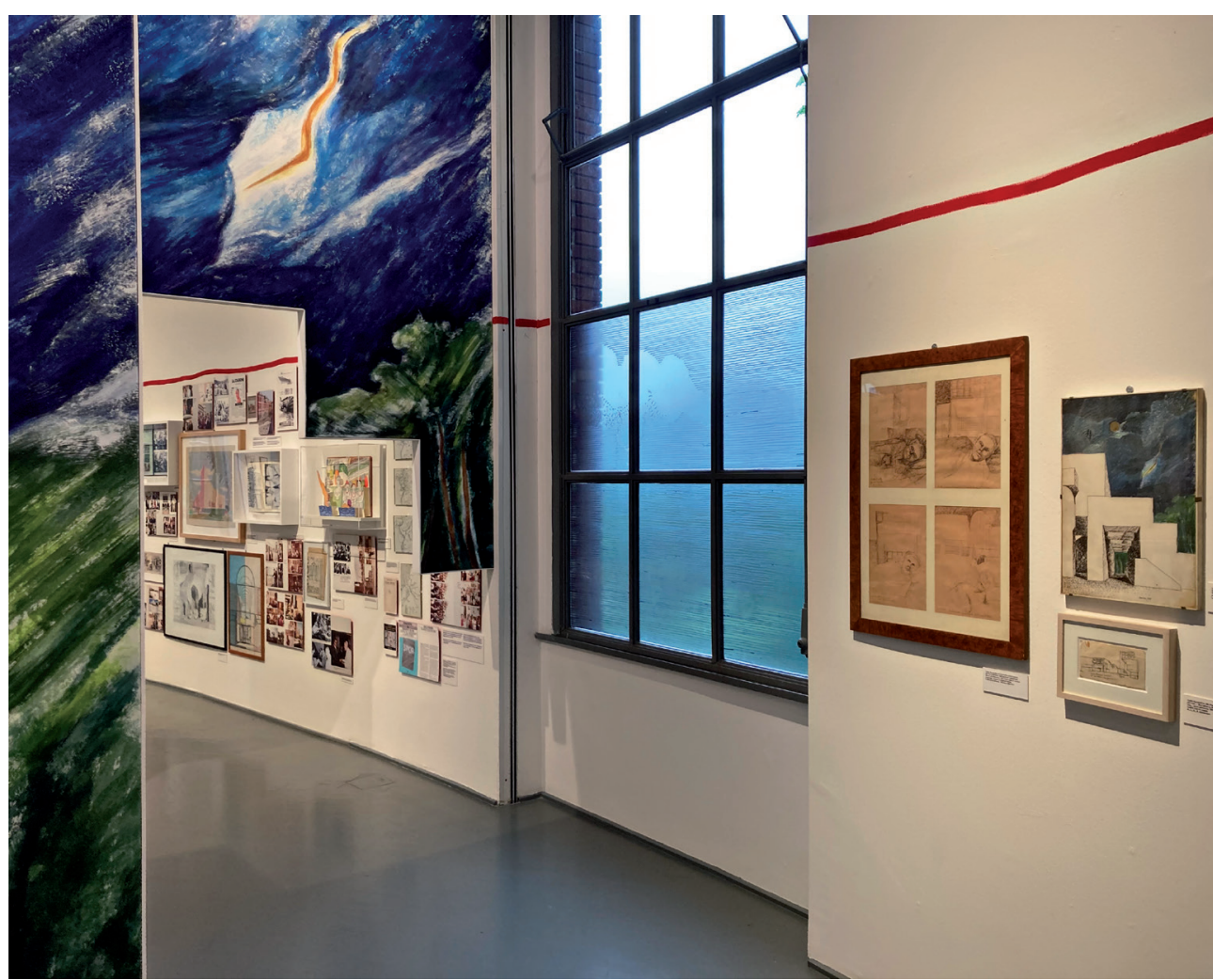

Figure 4. Entryway to the section dedicated to the high-school in Pesaro. The original of the study The High-School in Giorgione's Storm (1978) is on the right; Indian ink wax pastels, 50 x $35 \mathrm{~cm}\left[19^{1} / 2 \times 13^{1} / 2\right.$ in.], collection Luciana Tissi. 
an architect's idea as it conflates design thinking at multiple levels in one synthetic and potent image. The perspective view is where the figurative power of an architect coalesces into a compelling vision and is put to the test - a challenge that Aymonino cherished, for himself in the first place. It is also, though, the one mode of architectural representation that everybody understands: the one way in which the architectural idea is (or is not) able to stir people's imagination and emotions.

The exhibition provides an abundance of drawings and physical models of Aymonino's most important works: from the early projects with Ludovico Quaroni and Mario Ridolfi of the 1950s, to his first important realizations (such as the Palazzina in via Arbia in Rome, 1960-61), and the first important interventions within historic centers (such as the competition entry for the Teatro Paganini in Parma, 1965), to the master works of his maturity: the Gallaratese housing complex in Milan (1967-72) and the school campus in Pesaro (1970-84). The overview is completed with the documentation of major national and international competitions (such as the university campuses of Florence, Cagliari and Calabria, 1971-73, the housing complex for Cannaregio, Venice, 1978-80, and the extension for the Prado Museum in Madrid, 1995), as well as the late works in southern Italy (the Theater in Avellino, 1987 and Piazza Mulino in Matera, 198791) and studies and projects for his own Rome: the vision for the large archeological district of the Imperial Fora (1982-84), the reconstruction of the Colossus (1982-84) and the refurbishing of the Capitol Museums (19932005). (Figs. 5, 6.)

Around the core of professional works, and drawings for and about them (sometimes done, similarly to his dear friend and colleague Aldo Rossi, after the definition of the project or the realization of the work, in an ongoing process of formal and spatial research), the exhibition weaves through also a series of documents of Aymonino's rich and complex life, both in his personal stories and within the public sphere, namely for his political engagement with the Italian Communist Party (PCI). As an outcome of this engagement, came also Aymonino's unique experience in civic administration when he served as Alderman for Interventions in the Historic Center for the Municipality of Rome in the 1980s, during a period of $\mathrm{PCl}$ led civic administrations.

For Aymonino, politics and architecture really never merged completely (or substantially, as in in the case of other famous modern architects who served in public administrations, such as Marinus Dudok in Hilversum, The Netherlands, or Ernst May in Frankfurt and Martin Wagner in Berlin), and Aymonino clearly understood the need to speak different languages, relative to the specific different fields of operation, with only occasional and limited overlapping. Clear, though, were Aymonino interests and passions in both realms, to which he remained faithful throughout his career. "Between Form and Reform," as late Roman architectural historian Mario Manieri-Elia once commented about his friend and colleague. ${ }^{5}$ 


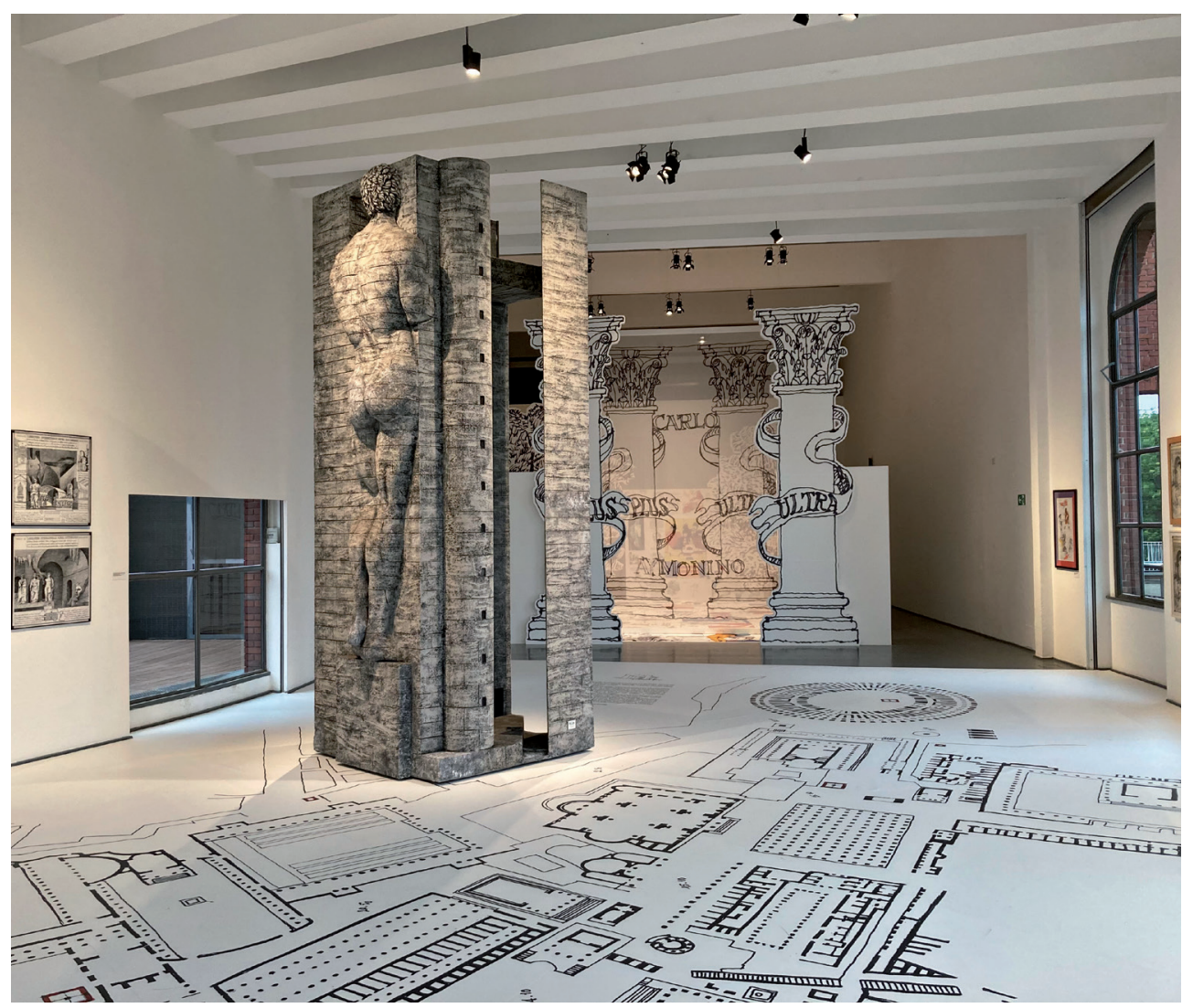

Figure 5. Section dedicated to the project for the reconstruction of the Colossus in Rome (1982-84). Polyurethane foam, scale 1:10. Comune di Modena, Collezione Galleria

Civica. In the background, "Carlo Aymonino's Wunderkammer," a curated installation with reproductions (on partition walls and carpet floor) of sketches and drawings.

Similar was the case for academic administration, in which Aymonino had plunged in the late 1970s by taking the reins, as Director (but comparable to the current office of Rector), of the Istituto Universitario di Architettura (IUAV), in Venice. He was elected to the office after the tumultuous and disruptive years of the early 1970s, during Carlo Scarpa's unhappy stint at academic administration, after he had succeeded IUAV's visionary leader of several decades, Giuseppe Samonà (who had invited Aymonino to the IUAV in the first place, as a young faculty, in 1963). As IUAV Director, Aymonino put to good use his innate and distinctive capacity at organizing teams and gathering talents, as he had done with great foresight when he invited a then fairly unknown young architect and theorist, Aldo Rossi, to join him as his assistant in Venice - Aymonino and Rossi had met through the same national political circles of the $\mathrm{PCl}$ and when Aymonno, since the mid-1950s, had started to collaborate as Roman correspondent for Ernesto Nathan Rogers' Casabella, where Rossi was a regular editor. By renewing with a more modern and more cross-disciplinary approach Saverio Muratori's legacy of urban morphology studies at the IUAV, Aymonino launched and pursued, also by leveraging Rossi's interests and expertise, 


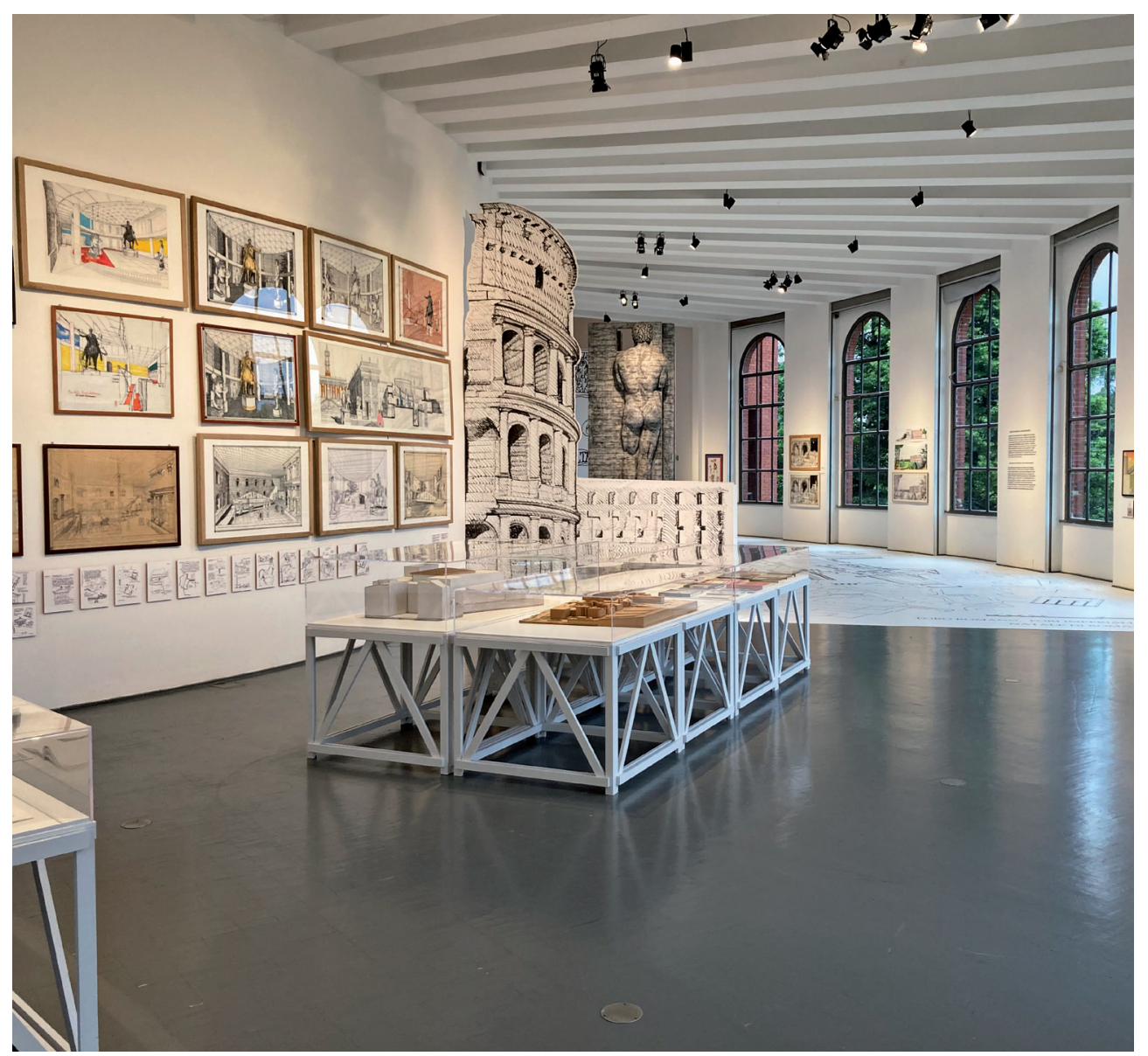

Figure 6. Section for the project for the Capitol Museums in Rome (1993-2005).

a whole new season of urban studies, thus helping create Rossi's springboard for his landmark and once-in-a-century book The Architecture of the City of 1966. As Rafael Moneo has pointed out, "one of Carlo Aymonino's virtues was the extraordinary generosity he showed towards his architect colleagues whom he respected and loved. We need only think of his relationship with Aldo Rossi. Carlo's support enabled Aldo to enjoy a series of unique opportunities that were very helpful in the consolidation of his career." " Albeit with less recognition, Aymonino eventually went on to publish himself two very important books, illustrated also by his insightful sketches: Origini e sviluppo della città moderna (Origins and Growth of the Modern City, 1965) and I/ significato delle città (The Meaning of Cities, 1975). The exhibition features also the originals of all these landmark books, as well as other publications by Aymonino and his research teams. Those research documents clearly show his personality of a "thinking architect, operating in our current difficult conditions," as he liked to see himself and those around him sharing his principles and approach. ${ }^{7}$ In spite of Aymonino's caution in establishing a causation relationship between analysis and design, he himself acknowledged, with a realism clearly resonating from his political culture, that his research efforts at 


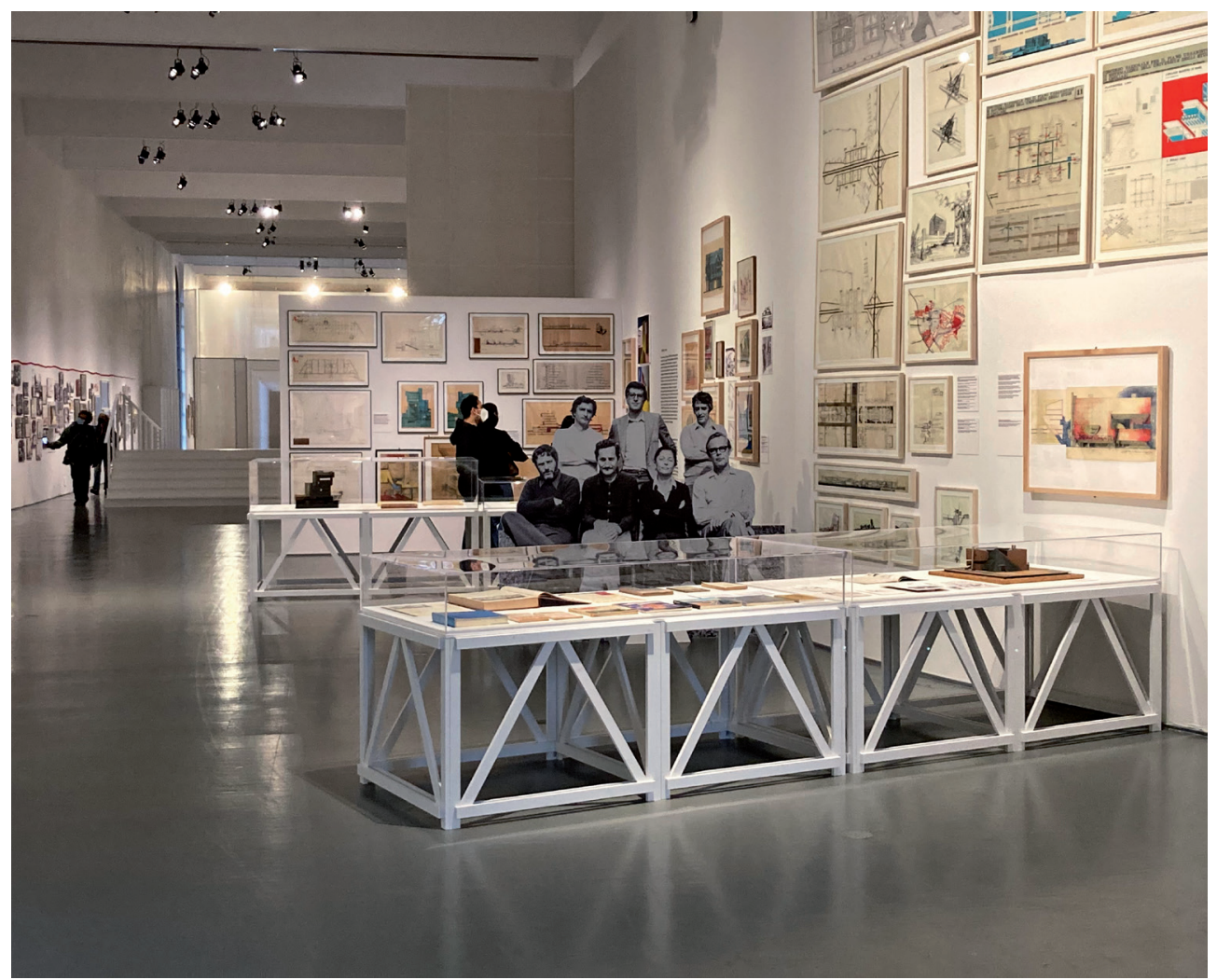

Figure 7. Section dedicated to projects of the 1970s (including those for the universities of Florence, 1971, and Cagliari, 1972), with a blown-up picture of some members of the "Gruppo Architettura" at the IUAV: (from left to right, standing) Raffaele Panella, Gianni Fabbri and Mauro Lena; (from left to right, seated) Luciano Semerani, Gianugo Polesello, Giusa Marcialis, Carlo Aymonino.

the IUAV (with the team known as "Gruppo Architettura") were aimed at defining "a scientific basis for the comprehension of the city that would permit a critical insertion of the project into urban growth." ${ }^{8}$ (Fig. 7.)

In summation, the exhibition does a great job at illustrating the works and the character of the man, the citizen, the architect and the scholar, in all his achievements, disappointments, and passions. Aymonino's artistic and intellectual research and critical practice emerges in its whole richness and complexity for a long overdue homage to someone whom Triennale's Artistic Director Lorenza Baroncelli has aptly called "an architect capable of traversing various phases of the second half of the twentieth century with original style and absolute lightness... [while making] an enormous contribution to the architecture of the postwar period, [as well as fulfilling] important political and institutional roles..." 9

From the rich catalog that accompanies the exhibition, featuring a series of essays by various critics, colleagues and friends (in addition to Paolo Rosselli's beautiful photographic coverage of the Gallaratese complex in Milan and the Pesaro campus), Luciano Semerani's testimonial stands out as one of the most insightful when he remembers Aymonino as someone who just "loved architecture and art, and loved detours stimulated by 
intellectual curiosity... a very free man... [who] needed and enjoyed bringing people together. ... not a salon-dweller [but someone who] loved to surround himself and cultivate friendship." 10

The complexity of Aymonino's life beautifully emerges out of the exhibition, also through a timeline of documents (sketches, photos, letters) and a Wunderkammer of his sketches and "visual dreams," not so much as a series of "betrayals," but out of what I would better call human, artistic and intellectual curiosity. In fact, as witty and somewhat self-deprecating as Aymonino himself would have liked (he did call himself a "traitor"), the exhibition title, in my opinion, may limit and constrict once more his true legacy. Just because, as a free spirit, he appreciated the beauty of life and the many possibilities of artistic explorations, he should not be labeled in an apparently superficial way. Again, with Moneo, "finding himself with the choice between life and work, Aymonino chose life, also taking on all the associated burdens in relation to the community." ${ }^{11}$ More than a "traitor," we should remember and appreciate Aymonino as a curious "man/citizen/ architect" (as Rogers would have liked to put it). A "gentle and urbane man" (in Peter Eisenman's words ${ }^{12}$ ), an engaged citizen, and a visionary architect who knew how to put personal, civic and professional passions into perspective.

\section{Notes}

1. Stefano Boeri, foreword to Carlo Aymonino. Loyalty to Betrayal, catalog of the exhibition at the Milan Triennale (14 May - 22 August 2021), ed. Manuel Orazi (Milan: Electa, 2021), 10 .

2. Maurizio Sabini, "Drawing is Theory," paper presented at the session "Drawing as Theory," key-panelist Marco Frascari, 89th ACSA (Association of Collegiate Schools of Architecture) annual conference, Baltimore MD, USA, March 16-20, 2001.

3. Carlo Aymonino, "Intervista sulla vita," in Claudia Conforti, Carlo Aymonino. L'architettura non è un mito (Rome: Officina, 1980), 174; transl. in Carlo Aymonino. Loyalty to Betrayal, 42.

4. Aymonino, "Intervista," 50.

5. Mario Manieri-Elia, introducing Carlo Aymonino for a lecture at the IUAV, Venice, early 1980s (my personal recollection).

6. Rafael Moneo, testimonial, ed. Federica Morgia, in Carlo Aymonino. Loyalty to Betrayal, 316-19 (316).

7. Carlo Aymonino, "Premessa," preface to I/ significato delle città (Venice, It.: Marsilio, 2000), 9-11 (10); or. ed. (Bari, It.: Laterza, 1975).

8. Carlo Aymonino, "Pour une université de masse," L'architecture d'aujourd'hui 181 (1975): 63-64, transl. in Carlo Aymonino. Loyalty to Betrayal, 94.

9. Lorenza Baroncelli, foreword to Carlo Aymonino. Loyalty to Betrayal, 12.

10. Luciano Semerani, testimonial, ed. Giovanni Damiani, in Carlo Aymonino. Loyalty to Betrayal, 334-37 (334, 336).

11. Moneo, testimonial, 318.

12. Peter Eisenman, "A Gentle Man," foreword to Carlo Aymonino (London: Academy Editions, 1996) and Eisenman's testimonial, in Carlo Aymonino. Loyalty to Betrayal, 314-15 (314). 